\title{
Magnetska rezonancija i kompjutorizirana tomografija u dijagnostici cističnih lezija gušterače
}

\section{Magnetic resonance and computed tomography imaging of cystic pancreatic lesions}

\author{
Nikša Petrović1 ${ }^{1}$ Zrinka Matana Kaštelan ${ }^{2}$, Tiana Grubešić ${ }^{1}$, Damir Miletić
}

\begin{abstract}
Sažetak. Cistične lezije gušterače su raznovrsna grupa lezija s vrlo širokom histološkom diferencijacijom, od benignih tvorevina do invazivnih malignih tumora. Predstavljaju klinički problem budući da je etiologija tih promjena vrlo raznolika, tijek bolesti često asimptomatski, a potencijalno su malignog karaktera. Tijekom godina broj pacijenata s dijagnosticiranim cističnim lezijama gušterače je značajno porastao prvenstveno zbog napretka radioloških tehnika i starenja populacije. Kompjutorizirana tomografija i magnetska rezonancija predstavljaju izvrsne slojevne slikovne metode za otkrivanje i karakterizaciju cističnih lezija te su predvodnice u dijagnostici i temelj odluke o terapijskom pristupu. U radu ćemo ukratko prikazati spektar najčešćih cističnih lezija gušterače i njihovu radiološku prezentaciju.
\end{abstract}

Ključne riječi: cistične lezije; gušterača; slojevne slikovne metode

Abstract. Cystic lesions of the pancreas are histologically diverse group of lesions, from benign to the invasive malignant lesions. Due to diverse etiology, sometimes asymptomatic course of the disease and potentially malignant character they represent significant clinical problem. With the development of radiological techniques and aging of population the number of diagnosed cystic lesion increases. Computed tomography and magnetic resonance imaging are excellent modalities for both initial detection and later characterization of cystic pancreatic lesions and they have leading role both in diagnostic and therapy planning. In this article we will present the spectre of most common cystics lesion of the pancreas and their radiologic presentation.

Key words: cystic lesion; diagnostic imaging; pancreas

\author{
${ }^{1}$ Klinički zavod za radiologiju, KBC Rijeka, \\ Rijeka \\ ${ }^{2}$ Katedra za radiologiju, Medicinski fakultet \\ Sveučilišta u Rijeci, Rijeka
}

"Dopisni autor:

Zrinka Matana Kaštelan, dr. med.

Krešimirova 42, 51000 Rijeka

e-mail: zmkastelan@gmail.com 


\section{UVOD}

Cistične lezije gušterače se često slučajno uočavaju kod pacijenata koji se podvrgnu slojevnim slikovnim pregledima abdomena. Prevalencija iznosi 2,1 - 2,6\% na kompjutoriziranoj tomografiji (engl. computed tomography; CT) $)^{1,2}$, odnosno $13,5-45 \%$ na magnetskoj rezonanciji (engl. magnetic resonance, $\mathrm{MR})^{3,4} \mathrm{u}$ asimptomatskih osoba, a taj je broj u osoba starijih od 70 godina oko $40 \%{ }^{3}$. Razlozi se $s$ jedne strane mogu pronaći u

Kompjutorizirana tomografija (engl. computerised tomography; CT) i magnetska rezonancija (MR) predstavljaju izvrsne slojevne slikovne metode za otkrivanje i karakterizaciju cističnih lezija te su predvodnice u dijagnostici i temelj odluke o terapijskom pristupu.

sve češćoj uporabi i razvoju slojevnih tehnika snimanja, CT-a i MR-a, a s druge u starenju populacije. Uočavaju se sve manje lezije, a prevalencija većih od $2 \mathrm{~cm}$ se pokazala stabilnom i iznosi $0,8 \%{ }^{5}$. Diferencijalna dijagnoza cističnih lezija gušterače je široka, od netumorskih koje u pravilu ne treba liječiti ukoliko nisu simptomatske, cisti s visokim rizikom koje treba pratiti i neoplastičnih koje zahtijevaju kirurško liječenje. Nadalje, cistične lezije se mogu dijeliti na lezije koje stvaraju mucin (intraduktalne papilarne mucinozne neoplazme i mucinozne cistične neoplazme) i one koje ne stvaraju mucin. Javljaju se sporadično ili u nekim sindromima (npr. Von Hippel-Lindau (VHL), policistična bolest bubrega). Najčešće cistične lezije gušterače su intraduktalna papilarna mucinozna neoplazma (IPMN), serozni cistadenom (SCA), mucinozna cistična neoplazma (MCN), solidna pseudopapilarna neoplazma (SPN), cistični pankreatični neuroendokrini tumor (cPNET) i upalne kolekcije ${ }^{6-8}$. Velike cistične lezije sa zabri- njavajućim karakteristikama češće se pronalaze u starijih osoba s komorbiditetima. Ponekad se nekrotično degenerirani solidni tumori prezentiraju kao cistične lezije.

\section{MR I CT U DIJAGNOSTICI CISTIČNIH LEZIJA} GUŠTERAČE

MR i CT su podjednake dijagnostičke točnosti u karakterizaciji cističnih lezija gušterače ${ }^{9,10}$, no MR je senzitivnija metoda zbog bolje kontrastne rezolucije. MR abdomena u kombinaciji s MRCP-om pokazala se kao tehnika izbora jer je neinvazivna, nema ionizacijskog zračenja, točnija je u procjeni povezanosti s glavnim pankreatičnim vodom, ima veću sposobnost uočavanja muralnih nodusa i septa kao i uočavanja multiplih cističnih lezija ${ }^{11}$. Specifičan MR protokol za gušteraču uključuje T1 i T2 mjerene slike, difuzijski gradijent i MRCP sekvencu kao i postkontrastne dinamičke T1 presje$\mathrm{ke}^{12}$. CT po pankreatičnom protokolu se koristi ukoliko je potrebna detekcija kalcifikata, kod pacijenata s akutnim pankreatitisom, u slučaju sumnje na karcinom gušterače ili recidiv karcinoma, kod procjene zahvaćenosti krvnih žila, peritonealne i metastatske bolesti ili kao alternativna metoda za pacijente koji iz nekog razloga ne mogu na $M R^{13}$. Potrebno je odrediti veličinu i broj lezija, utvrditi eventualnu povezanost s glavnim pankretičnim vodom te suspektne karakteristike koje ukazuju na malignu transformaciju, a prilikom praćenja uočiti postoji li porast veličine (tablica 1). Kod cističnih lezija manjih od $10 \mathrm{~mm}$ je vrlo teško dijagnosticirati tip ciste ${ }^{14}$. Cistične lezije gušterače $s$ malignim potencijalom treba pratiti sve dok je lezija resektabilna, a pacijent u stanju podnijeti kirurški zahvat ${ }^{13}$.

\section{UPALNE KOLEKCIJE}

Oko 80 \% svih cističnih lezija gušterače su upalne kolekcije. Javljaju se u pacijenata s poznatom

Tablica 1. Slikovne karakteristke cističnih lezija visokog rizika

1. Muralni nodul ili solidna komponenta unutar ciste

2. Glavni pankreatični vod širi od $5 \mathrm{~mm}$

3. Promjena širine glavnog pankreatičnog voda uz atrofiju ostalog tkiva gušterače

4. Lezija veća od $3 \mathrm{~cm}$

5. Porast veličine ciste veći od $3 \mathrm{~mm}$ po godini dana 
anamnezom akutnog ili kroničnog pankreatiti$\mathrm{sa}^{15,16}$, češće u muškaraca. Uključuju akutnu peripankreatičnu tekuću kolekciju, akutnu nekrotičnu kolekciju, pseudocistu i engl. walled-off nekrozu. Nastaju zbog hemoragične nekroze masnog tkiva uslijed djelovanja pankreatičnih enzima. Upalne kolekcije nemaju epitelni pokrov i zbog toga nisu prave epitelne ciste. Za stvaranje stijenke potrebno je obično četiri ili više tjedana pa kolekcije u ranoj fazi akutnog pankreatitisa uopće nemaju stijenku. Kad se formira, stijenka je građena od

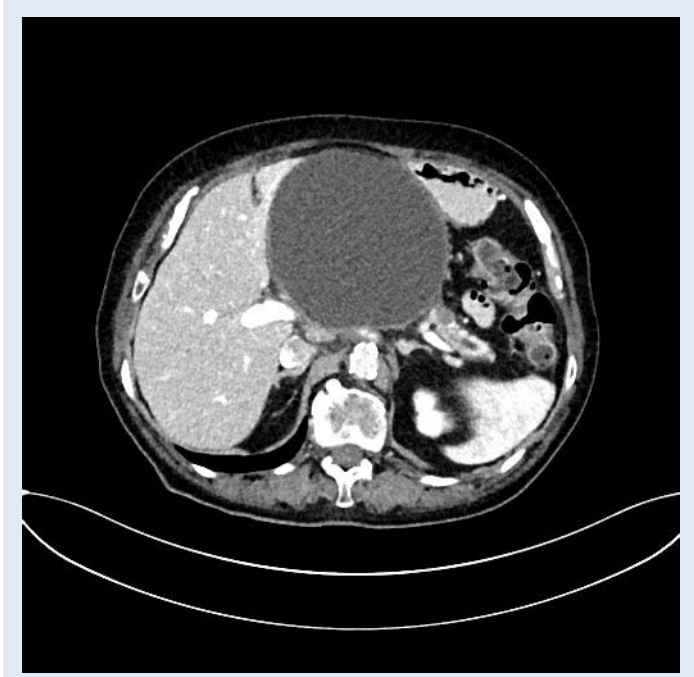

Slika 1. CT na aksijalnom presjeku pokazuje homogenu, dobro ograničenu pseudocistu gušterače.

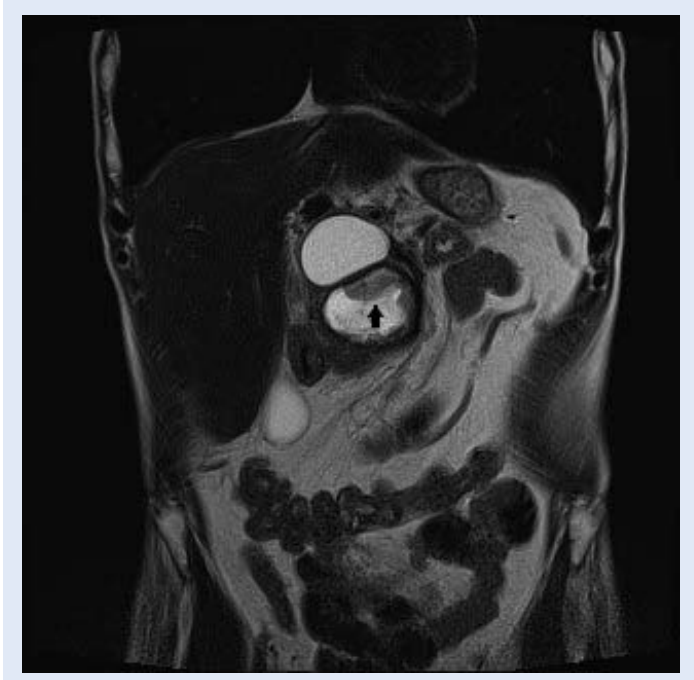

Slika 2. MR na koronalnom presjeku u T2 mjerenom vremenu pokazuje dvije upalne kolekcije gušterače od kojih je proksimalnija homogena prikaza, dok je druga ispunjena heterogenim raspadnim produktima (crna strjelica). granulacijskog i fibroznog tkiva. Kako nemaju solidne komponente, upalne kolekcije nemaju niti maligni potencijal. Na CT-u se vide kao okrugle ili ovalne hipodenzne lezije ${ }^{17-19}$, ponekad s raspadnim, nekrotičnim ili hemoragičnim produktima koji se na MR-u jasnije diferenciraju kao visoki signal u T1 mjerenom vremenu (slika 1, slika 2). Većina ih u konačnici spontano regredira. Ako su asimptomatske, ne zahtijevaju daljnje praćenje. U slučajevima kad su simptomatske i kad dođe do komplikacija poput kompresije okolnih struktura, krvarenja ili infekcije, potreban je intervencijski zahvat, najčešće endoskopska drenaža. Ponekad njihova radiološka diferencijacija u odnosu na mucinozne cistične lezije nije u potpunosti sigurna te je potrebno praćenje.

\section{SEROZNI CISTADENOM (SCA)}

Serozni cistadenom je benigna, dobro ograničena, serozna cistična lezija. Incidencija je veća kod ženskog spola (75 \%), posebice u 5. i 6. desetljeću života, a pojavljuje se nerijetko i kod VHL bolesti20-22. Može se naći bilo gdje u gušterači i najčešće je usputan nalaz, bez kliničkog značaja (tzv. incidentalom). Ciste su obrubljene kubičnim epitelom bogatim glikogenom, citološki benignih karakteristika. SCA ne invadira okolne strukture, već ih potiskuje te iznimno rijetko komunicira s glavnim pankreatičnim vodom. Na CT-u se prikazuje kao hipodenzna, lobulirana, mikrocistična lezija ponekad s karakterističnim izgledom „saća”, a u manjem broju slučajeva (15 \%) je makrocističnog izgleda (slika 3, slika 4). Obično je građen od šest ili više komorica koje su velike od nekoliko $\mathrm{mm}$ do $2 \mathrm{~cm}^{23}$. Na MR-u je cistična komponenta tipično visokog signala u T2 mjerenim slikama i niskog signala u T1 mjerenim slikama, a septe su tanke i postkontrastno se imbibiraju na odgođenim snimkama. U manje od 30 \% SCA vidljiv je patognomonični centralni ožiljak (na CT-u hiperdenzan, a na MR-u niskog signala u T1 mjerenim slikama $)^{12,13}$ koji nakon primjene kontrasta pokazuje odgođenu imbibiciju. Unutar ožiljka se mogu vidjeti i kalcifikati koji se također smatraju patognomoničnim znakom. Jedna od multicentričnih studija koja je uključivala više od 2500 pacijenata sa SCA zaključila je kako rizik od razvoja cistadenokarcinoma iznosi $0,1 \%{ }^{24}$. Maligna transforma- 


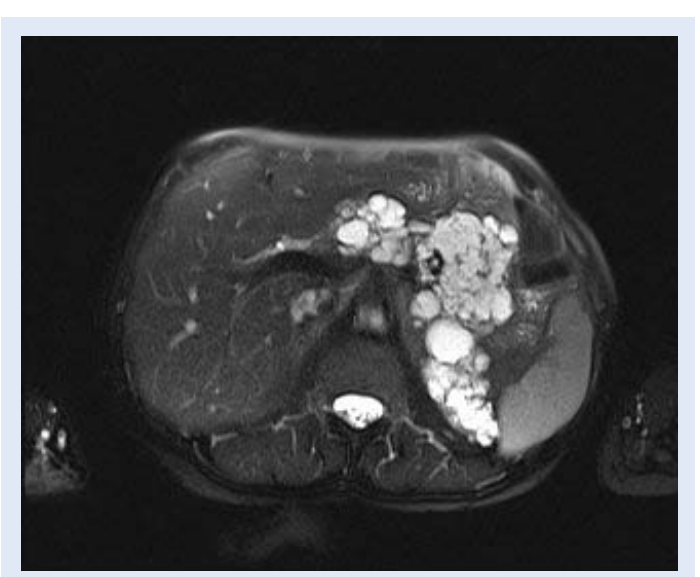

Slika 3. MR na aksijalnom presijeku u T2 mjerenom vremenu pokazuje "saćast" izgled seroznog cistadenoma kod pacijenta s von Hippel-Lindau bolesti.

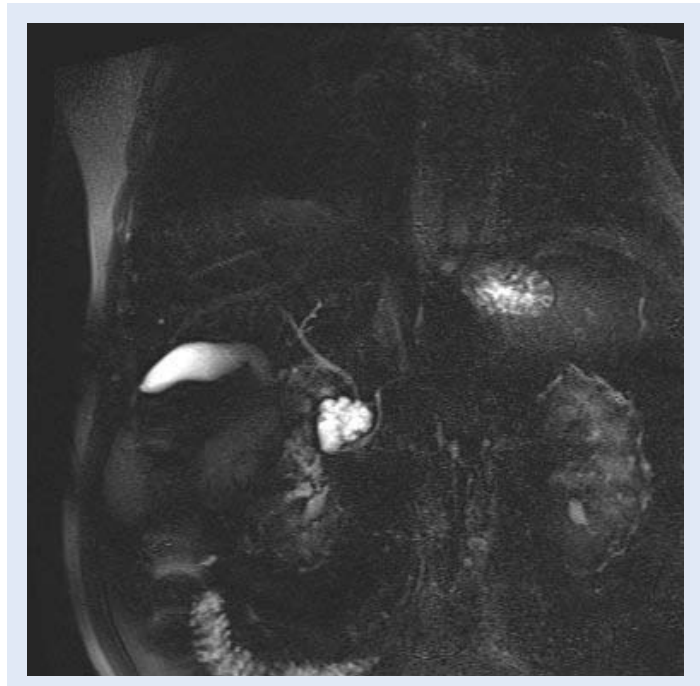

Slika 4. MRCP presjek pokazuje makrocističnu varijantu seroznog cistadenoma u glavi gušterače.

cija je opisana, no dosad je u literaturi zabilježeno manje od 10 slučajeva metastatskog seroznog cistadenoma ${ }^{25}$. Obzirom na navedeno, resekcija je indicirana kod simptomatskih ili kod brzorastućih lezija (većih od $4 \mathrm{~cm}$ ) u mlađih osoba.

\section{SOLIDNA PSEUDOPAPILARNA NEOPLAZMA (SPN)}

Solidna pseudopapilarna neoplazma predstavlja rijedak epitelni tumor s niskim malignim potencijalom. Češće se javlja kod žena (10:1), najčešće u 2. i 3. desetljeću života. U $59.3 \%$ pacijenata SPN se nalazi u trupu i repu gušterače ${ }^{26}$. Građena je od monomorfnih epitelnih stanica koje oblikuju solidne i pseudopapilarne strukture. Multicentrična metaanaliza pokazala je kako se najčešće klinički prezentira bolovima u trbuhu (63\%) ili su asimptomatske i slučajan nalaz $(38 \%)^{26}$. Na CT-u i MR-u prvenstveno se prikazuje kao dobro ograničena masa (prosječne veličine $8-10 \mathrm{~cm}$ ), sa solidnim tkivom periferne lokalizacije i znakovima centralne cistične degeneracije, nekroze i krvarenja. Navedene karakteristike daju joj heterogeni izgled na T1 i T2 mjerenim slikama, a važan dijagnostički pokazatelj predstavlja hipointezivna fibrozna kapsula koja nastaje kao reakcija na ekspanzivni rast tumora. Većina SPN su benignog karaktera. Budući da se lokalna invazija ili diseminacija mogu pronaći u do $20 \%$ pacijenata, preporuča se kirurška resekcija, a petogodišnje vrijeme preživljenja je oko $98 \%{ }^{26}$.

\section{MUCINOZNA CISTIČNA NEOPLAZMA (MCN)}

Mucinozna cistična neoplazma je cistični epitelni tumor građen od cilindričnog i kubičnog epitela koji stvara mucin i stromalnih stanica poput ovarijskih. Predstavlja oko $10 \%$ svih cističnih neoplazmi. Češće se javlja u žena $(20: 1)$ u 4. i 5. desetljeću života, a u 95 \% slučajeva je lokalizirana u trupu i repu gušterače ${ }^{27}$. Na CT-u se prikazuje kao dobro ograničena, velika, solitarna, makrocistična, hipodenzna lezija s tankim septama. Na MR-u ciste su karakteristično T2 visokog signala, a kapsula i septa T2 niskog signala ${ }^{28}$. Obično ne komunicira s glavnim pankreatičnim vodom. Kalcifikati koji su lamelirani poput ljuske jajeta (engl. "eggshell") i lokalizirani periferno jasnije su vidljivi CT-om nego MR-om. Oni su gotovo patognomoničan radiološki znak koji MCN razlikuje od ostalih cističnih lezija ${ }^{29}$. Kalcifikati, eventualna zadebljala septa i muralni nodusi koji se postkontrastno imbibiraju (te bolje uočavaju na MR-u) su radiološki znaci malignosti (slika 5 a,b). U studiji koja je uključivala 52 pacijenta $s$ MCN ove tri karakteristike bile su prisutne u $95 \%$ maligno promijenjenih lezija ${ }^{30}$. Budući da benigne MCN lezije imaju mogućnost preobrazbe u maligne u $12-20 \%^{27}$, za sve mucinozne cistične tumore kirurška resekcija je metoda izbora. Nakon resekcije dvogodišnje preživljenje u pacijenata $s$ maligno promijenjenim MCN je oko $67 \%$, a petogodišnje oko $50 \%{ }^{31}$. 

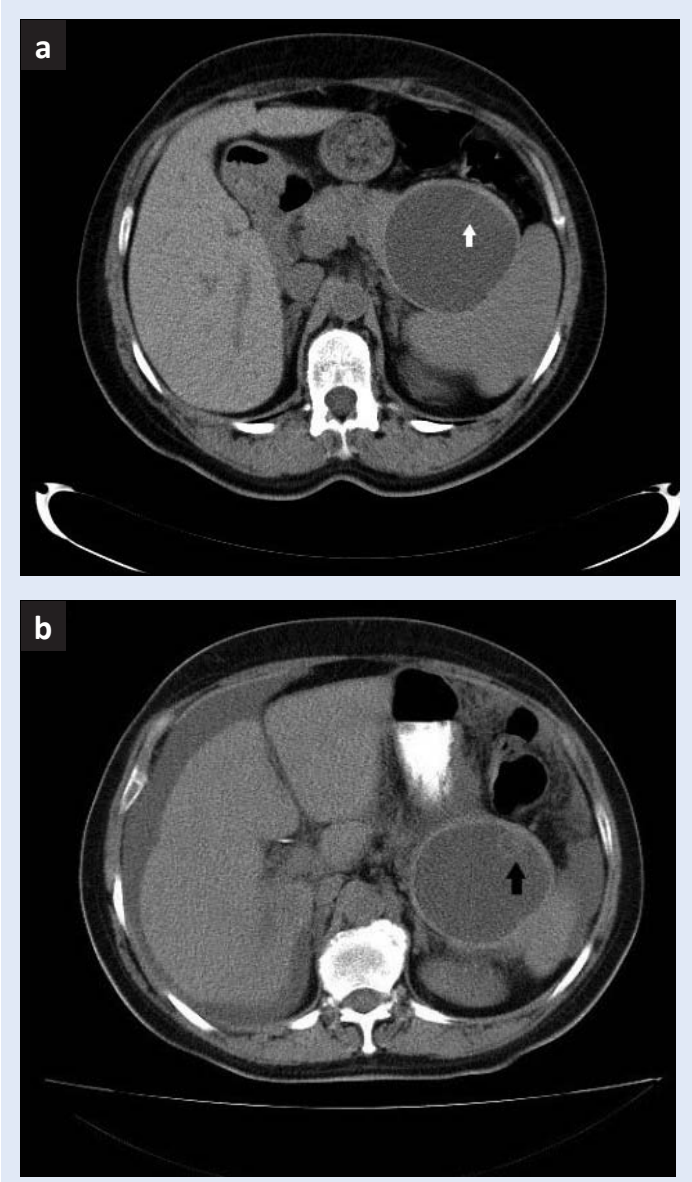

Slika 5a, b. CT na nativnim aksijalnim presjecima pokazuje mucinozni cistadenom s internim septama (bijela strjelica) te istu leziju nakon 18 mjeseci (b) gdje je vidljiv rubni muralni nodus (crna strjelica) u smislu maligne alteracije uz novonastali ascites.

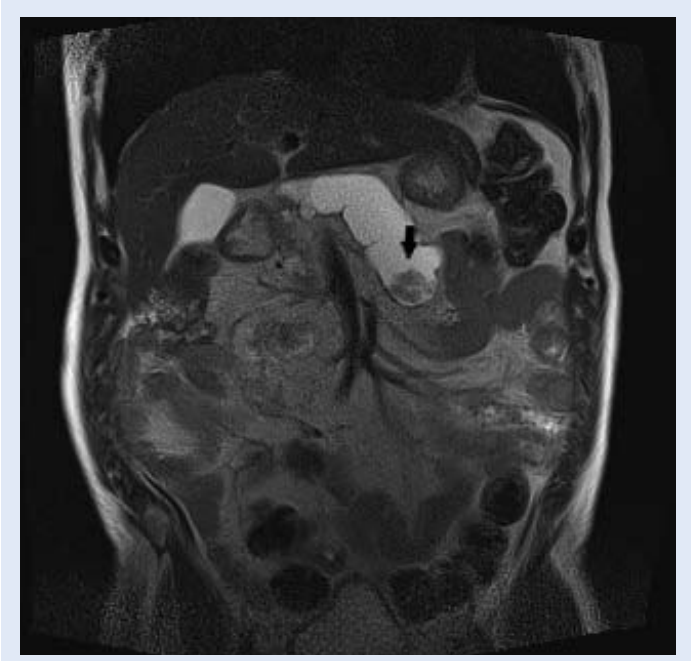

Slika 6. Na koronalnom MR presjeku u T2 mjerenom vremenu vidi se dilatacija glavnog pankreatičnog voda unutar kojeg se izdvaja solidna komponenta cističnog IPMN-a glavnog voda (crna strjelica), kao znak malignosti.
INTRADUKTALNA PAPILARNA MUCINOZNA NEOPLAZMA (IPMN)

Intraduktalna papilarna mucinozna neoplazma je heterogena grupa intraduktalnih epitelnih tumora koji proizvode mucin ${ }^{32}$. Jedina je od neoplazmatskih cističnih lezija koja ima blago višu incidenciju kod muškaraca i to najčešće u 6. desetljeću. Obično su asimptomatske. S obzirom na lokalizaciju i zahvaćenost vodova dijeli se na neoplazmu glavnog pankreatičnog voda (engl. main-duct, MD), postra-

Stoga bi individualizirani pristup svakom pojedinom pacijentu mogao smanjiti nepotrebna praćenja, skupe pretrage, a u slučaju CT-a i ionizirajuće zračenje. $\mathrm{Ne}$ smije se zaboraviti niti osjećaj nelagode kod pacijenata u iščekivanju dijagnoze, kao niti izlaganje možebitnom nepotrebnom kirurškom zahvatu. Cilj suvremene dijagnostike je sigurno izdvojiti pacijente s lezijama za koje je nedvojbeno potrebna resekcija.

ničnih vodova (engl. side-branch, SB) te miješani tip koji je kombinacija navedenih ${ }^{33}$. Na CT-u se vizualizira kao cistična pleomorfna, hipodenzna lezija u blizini glavnog pankreatičnog voda, odnosno na MR-u kao lezija niskog T1 i visokog T2 signala ${ }^{34}$. Morfološki variraju od makrocističnog uzorka s unilokularnom ili multilokularnom cistom do mikrocističnog uzorka gdje multiple interne tanke septe odvajaju sitne cistične prostore. IPMN je najčešće solitaran, no u $20-30 \%$ slučajeva može biti multifokalan, a u 5 - $10 \%$ slučajeva difuzno zahvatiti gušteraču ${ }^{35,36}$. Solidni dijelovi lezije pokazuju kontrastnu imbibiciju i znak su malignosti. S obzirom na to da posjeduje slične slikovne karakteristike kao i serozni i mucinozni cistadenom, ključan dijagnostički kriterij predstavlja komunikacija s pankreatičnim vodovima (slika 6) te njihova eventualna dilatacija. Ovdje superiornu i nezamjenjivu ulogu ima MRCP sekvenca koja najbolje vizualizira komunikaciju lezije s vodovi$\mathrm{ma}^{37}$, a difuzijske sekvence (engl. diffusion weighted imaging, DWI) MR-a služe za definiranje celularnosti, odnosno malignosti (slika 7a, b). Lezije glavnog voda i miješanog tipa maligno alteriraju podjednako često (38-68 \% i $38-65 \%$ ) dok IPMN postraničnih vodova koji je i najčešći mali- 

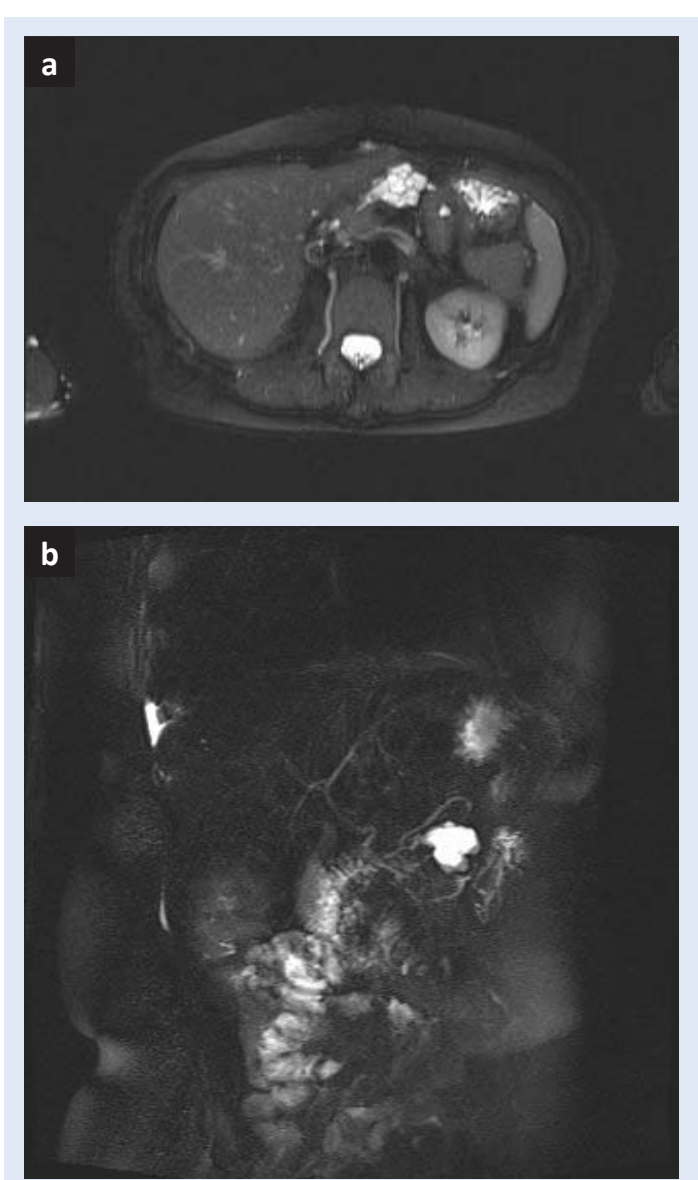

Slika 7a, b. MR na aksijalnom presjeku u T2 mjerenom vremenu pokazuje makrocističnu multilokularnu varijantu IPMN-a postraničnih vodova te (b) MRCP presjek koji najbolje pokazuje komunikaciju IPMN-a postraničnih vodova. gušterače s glavnim pankreatičnim vodom kao ključan detalj u njegovoj dijagnostici.

gno alterira u $12-47 \%^{38}$. S obzirom na navedeno, kod lezija glavnog pankreatičnog voda i miješanog tipa indiciran je kirurški zahvat, s radiološkim kontrolama jednom godišnje. Kod lezija postraničnih vodova odluka se donosi s obzirom na kliničku procjenu, starost i stanje pacijenta kao i nekih od morfoloških kriterija poput dilatacije glavnog voda, veličine i dinamike rasta lezije te eventualne solidne komponentne.

CISTIČNI PANKREATIČNI NEUROENDOKRINI TUMORI (CPNET)

Rijetko se javljaju i obično su nefunkcionalni. Najčešći su kod starijih pacijenata (> 60 god.), bez izražene spolne predilekcije ${ }^{39}$. Mogu biti sporadični ili u sklopu različitih sindroma (multipla endokrina neoplazija tip 1, VHL i tuberozna skle- roza) $)^{40,41}$. Na slikovnim pregledima teško ih je razlikovati od drugih cističnih neoplazmi gušterače, a većinom se prikazuju kao unifokalne, dobro ograničene cistične lezije, hipervaskularnog ruba. Ponekad su septirane ili sa solidnom komponentom $^{42}$. Za razliku od solidnih, kod cPNET-ova rjeđe se nađu nekroza, perineuralna i vaskularna invazija te metastaze ${ }^{39}$. Kirurška resekcija je metoda izbora, a petogodišnje preživljenje je veće od $85 \%$.

\section{OSTALE CISTIČNE LEZIJE GUŠTERAČE}

Ostale vrlo rijetke cistične lezije gušterače koje nemaju maligni potencijal uključuju ciste s pravim epitelom, mucinozne netumorske ciste te limfoepitelijalne ciste ${ }^{8}$. Duktalni adenokarcinom gušterače te izrazito rijedak adenokarcinom acinarnog tipa mogu biti cistično degenerirani te tako oponašati druge cistične lezije.

Trenutno važeći dobro strukturirani algoritmi i smjernice koji nas vode u postupanju s cističnim lezijama i definiraju daljnji terapijski pristup su američke: https://gi.org/guideline/managementof-pancreatic-cysts/ i europske: https://gut.bmj. com/content/67/5/789, no treba imati na umu kako ne pokrivaju svaki realni scenarij te je stoga budućnost $u$ individualiziranom pristupu prema svakom pojedinom pacijentu.

\section{ZAKLJUČAK}

Od suvremenih slojevnih slikovnih tehnika se očekuju podaci koji će omogućiti što točniju diferencijaciju benignih, potencijalno malignih i malignih cističnih lezija gušterače. Bez obzira na napredak dijagnostičkih mogućnosti CT-a i MR-a, klasifikacija cističnih lezija gušterače ostaje izazov. Glavna uloga radiologa je razlikovanje benignih lezija od onih s malignim potencijalom koje zahtijevaju praćenje i/ili terapiju. Relevantni podaci dobiveni suvremenim slikovnim metodama su veličina lezije, eventualna povezanost lezije $s$ glavnim pankreatičnim vodom te postojanje solidne komponente. Smjernice za pristup cističnim lezijama gušterače su se mijenjale tijekom godina, tako da ni trenutno važeći algoritmi i smjernice ne obuhvaćaju sve kliničke scenarije. Stoga bi individualizirani pristup svakom pojedinom pacijentu mogao smanjiti nepotrebna praćenja, 
skupe pretrage, a u slučaju CT-a i ionizirajuće zračenje. Ne smije se zaboraviti niti osjećaj nelagode kod pacijenata u iščekivanju dijagnoze, kao niti izlaganje možebitnom nepotrebnom kirurškom zahvatu. Cilj suvremene dijagnostike je sigurno izdvojiti pacijente s lezijama za koje je nedvojbeno potreban kirurški zahvat.

Izjava o sukobu interesa: Autori izjavljuju da ne postoji sukob interesa.

\section{LITERATURA}

1. Laffan TA, Horton KM, Klein AP, Berlanstein B, Siegelman SS, Kawamoto $S$ et al. Prevalence of unsuspected pancreatic cysts on MDCT. AJR Am J Roentgenol 2008;191: 802-7.

2. Spinelli KS, Fromwiller TE, Daniel RA, Kiely JM, Nakeeb A, Komorowski RA. Cystic pancreatic neoplasms: observe or operate. Ann Surg 2004;239:651-7.

3. Lee KS, Sekhar A, Rofsky NM, Pedrosa. Prevalence of incidental pancreatic cysts in the adult population on MR imaging. Am J Gastroenterol 2010;105:2079-84.

4. Zhang X-M, Mitchell DG, Dohke M, Holland GA, Parker L. Pancreatic cysts: depiction on single-shot fast spin-echo MR images. Radiology 2002;223:547-53.

5. Scheiman JM, Hwang JH, Moayyedi P. American gastroenterological association technical review on the diagnosis and management of asymptomatic neoplastic pancreatic cysts. Gastroenterology 2015;148:824-48.

6. Kloppel G, Kosmahl M. Cystic lesions and neoplasms of the pancreas. The features are becoming clearer. Pancreatology 2001;1:648-55.

7. Gorin AD, Sackier JM. Incidental detection of cystic neoplasms of the pancreas. Md Med J 1997;46:79-82.

8. Fernandez-Del Castillo C, Targarona J, Thayer SP, Rattner DW, Brugge WR, Warshaw AL. Incidental pancreatic cysts: clinicopathologic characteristics and comparison with symptomatic patients. Arch Surg 2003;138:427-34.

9. Del Chiaro M, Verbeke C, Salvia R, Klöppel G, Werner J, McKay $C$ et al. European experts consensus statement on cystic tumours of the pancreas. Dig Liver Dis 2013;45:703-11.

10. Lu X, Zhang S, Ma C, Peng C, Lv Y, Zou X. The diagnostic value of EUS in pancreatic cystic neoplasms compared with CT and MRI. Endosc Ultrasound 2015;4:324-9.

11. Elta GH, Enestvedt BK, Sauer BG, Lennon AM. ACG Clinical guideline: Diagnosis and Management of Pancreatic Cysts. Am J Gastroenterol 2018;113:464-79.

12. Franz D, Esposito I, Kapp AC, Gaa J, Rummeny EJ. Magnetic resonance imaging of less common pancreatic malignancies and pancreatic tumors with malignant potential. Eur J Radiol Open 2014;1:49-59.

13. The European Study Group on Cystic Tumours of the Pancreas. European evidence-based guidelines on pancreatic cystic neoplasms. Gut 2018;67:789-804.

14. Megibow AJ, Baker ME, Morgan DE, Kamel IR, Sahani DV, Newman E et al. Management of Incidental Pancreatic Cysts: A White Paper of the ACR Incidental Findings Committee. J AM Coll Radiol 2017;14:911-23.
15. Brugge W.R.: Diagnosis and management of cystic lesions of the pancreas. J Gastrointest Oncol 2015;6:375-88.

16. Spence RAJ., Dasari B, Love M, Kelly B, Taylor M. Overview of the investigation and management of cystic neoplasms of the pancreas. Dig Surg 2011;28:386-97.

17. Kopelman Y, Groissman G, Fireman Z. Cystic lesion of the pancreas. Gastrointest Endosc 2007;65:1074-5.

18. Scheiman JM. Cystic lesion of the pancreas. Gastroenterology 2005;128:463-9.

19. Dewhurst CE, Mortele KJ. Cystic tumors of the pancreas: imaging and management. Radiol Clin North Am 2012;50:467-86.

20. De Praeter G, Vanhoenacker F, Spiessens T. Serous (microcystic) adenoma of the pancreas. JBRBTR 2001;84:59.

21. Healy JC, Davies SE, Reznek RH. CT of microcystic (serous) pancreatic adenoma. J Comput Assist Tomogr. 1994;18:146-8.

22. Stern JR, Frankel WL, Ellison EC, Bloomston M. Solid serous microcystic adenoma of the pancreas. World J Surg Oncol 2007;5:26.

23. Sarr MG, Murr M, Smyrk TC, Yeo CJ, Fernandez-del-Castillo C, Hawes RH et al. Primary cystic neoplasms of the pancreas: neoplastic disorders of emerging importance-current state-of-the-art and unanswered questions. J Gastrointest Surg 2003;7:417-28.

24. Strobel O, Z'graggen $\mathrm{K}$, Schmitz-Winnenthal FH, Friess $\mathrm{H}$, Kappeler A, Zimmermann A et al. Risk of malignancy in serous cystic neoplasms of the pancreas. Digestion 2003;68:24-33.

25. Jais B, Rebours V, Malleo G, Salvia R, Fontana M, Maggino $L$ et al. Serous cystic neoplasm of the pancreas: a multinational study of 2622 patients under the auspices of the International Association of Pancreatology and European Pancreatic Club (European Study Group on Cystic Tumors of the Pancreas). Gut 2016;65:305-12.

26. Law JK, Ahmed A, Singh VK, Akshintala VS, Olson MT, Raman SP et al. A systematic review of solid-pseudopapillary neoplasms: are these rare lesions? Pancreas 2014;43:331-7.

27. Tanaka M.: International consensus on the management of intraductal papillary mucinous neoplasm of the pancreas. Ann Transl Med 2015;3:286.

28. Sarr MG, Carpenter HA, Prabhakar LP, Orchard TF, Hughes $\mathrm{S}$, van Heerden JA et al.-Clinical and pathologic correlation of 84 mucinous cystic neoplasms of the pancreas: can one reliably differentiate benign from malignant (or premalignant) neoplasms? Ann Surg 2000; 231:205-12.

29. Sahani DV, Kadavigere R, Saokar A, Fernandez-del CastiIlo C, Brugge WR, Hahn PF. Cystic pancreatic lesions: a simple imaging-based classification system for guiding management. Radiographics 2005;25:1471-84.

30. Procacci C, Carbognin G, Accordini S, Biasiutti C, Guarise A, Lombardo $\mathrm{F}$ et al. CT features of malignant mucinous cystic tumors of the pancreas. Eur Radiol 2001;11:162630.

31. Yoon WY, Brugge WR. Pancreatic cystic neoplasms: diagnosis and management. Gastroenterol Clin North Am 2012;41:103-18.

32. Yamada M, Kozuka S, Yamao K, Nakazawa S, Naitoh $Y$, Tsukamoto Y. Mucin-producing tumor of the pancreas. Cancer 1991;68:159-68. 
33. Zamboni G, Scarpa A, Bogina G, lacono C, Bassi C, Talamini $G$ et al. Mucinous cystic tumors of the pancreas: clinicopathological features, prognosis, and relationship to other mucinous cystic tumors. Am J Surg Pathol 1999;23:410-22.

34. Kalb B, Sarmiento JM, Kooby DA, Adsay VN, Martin DR. MR imaging of cystic lesions of the pancreas. RadioGraphics 2009;29:1749-65.

35. Farrell JJ, Brugge WR. Intraductal papillary mucinous tumor of the pancreas. Gastrointest Endosc 2002;55:70114.

36. Sahani DV, Lin DJ, Venkatesan AM, Sainani N, Mino-Kenudson M, Brugge WR et al. Multidisciplinary approach to diagnosis and management of intraductal papillary mucinous neoplasms of the pancreas. Clin Gastroenterol Hepatol 2009;7:259-69.

37. Waters JA, Schmidt CM, Pinchot JW, White PB, Cummings OW, Pitt HA et al. CT vs MRCP: optimal classification of IPMN type and extent. J Gastrointest Surg 2008;12: 101-9.
38. Stark A, Donahue TR, Reber HA, Hines OJ. Pancreatic cyst disease: a review. JAMA 2016;315:1882-93.

39. Singhi AD, Chu LC, Tatsas AD, Shi C, Ellison TA, Fishman EK et al. Cystic pancreatic neuroendocrine tumors: a clinicopathologic study. Am J Surg Pathol 2012;36:1666-73.

40. Pieterman $C R$, Vriens MR, Dreijerink KM, van der Luijt RB, Valk GD. Care for patients with multiple endocrine neoplasia type 1: the current evidence base. Fam Cancer 2011;10:157-71

41. Maher ER, Neumann HP, Richard S. von Hippel-Lindau disease: a clinical and scientific review. Eur J Hum Genet 2011;19:617-23.

42. Gaujoux S, Tang L, Klimstra D, Gonen M, Brennan MF, D'Angelica $\mathrm{M}$ et al. The outcome of resected cystic pancreatic endocrine neoplasms: a case-matched analysis. Surgery 2012;151:518-25.

43. Bordeianou L, Vagefi PA, Sahani D, Deshpande V, Rakhlin $E$, Warshaw AL et al. Cystic pancreatic endocrine neoplasms: a distinct tumor type? J Am Coll Surgery 2008;206: 1154-8. 